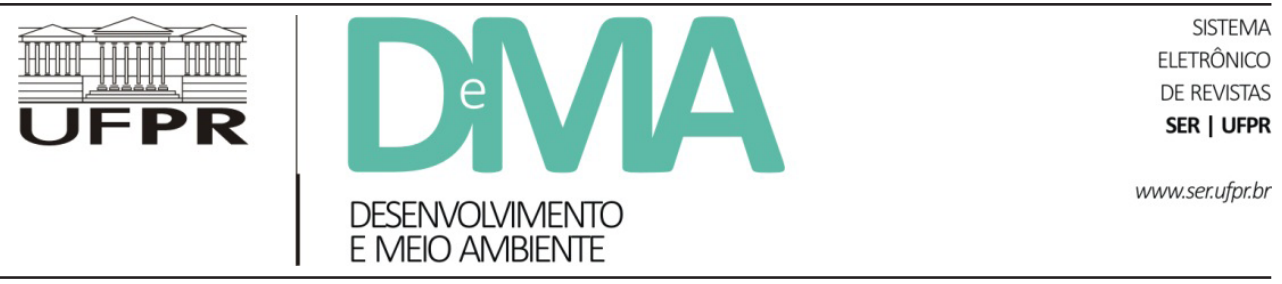

\title{
Resistência social na Caatinga árida: a narrativa de quem ficou no colapso ambiental
}

\section{Social Resistance in the Arid Caatinga: The Narrative of those who Remained in the Environmental Collapse}

\author{
Otacilio Antunes SANTANA ${ }^{1 *}$ \\ ${ }^{1}$ Universidade Federal de Pernambuco (UFPE), Recife, PE, Brasil. \\ *E-mail de contato: otaciliosantana@gmail.com
}

Artigo recebido em 19 de outubro de 2015, versão final aceita em 23 de maio de 2016.

RESUMO: A região analisada é historicamente um espaço de conflitos e de uma "violência fundadora", situada acima do médio São Francisco, entre as cidades de Ibimirim e Cabrobó (Pernambuco/Brasil). A presença desses conflitos, associada ao colapso ambiental causado pelo neoextrativismo local e ao clima árido, são fortes indícios para influenciarem a dinâmica populacional. Porém, o contrário é observado na região. A manutenção da população na região é corroborada pelo baixo valor de emigração e pelas narrativas. Por isso, variáveis ambientais e sociais foram coletadas e analisadas para avaliar se a ausência de uma dinâmica populacional é motivada por uma resistência social. Assim, o objetivo deste trabalho foi analisar o contexto ambiental e a narrativa de quem ficou no colapso da matéria-prima na Caatinga Árida pós-neo-extrativismo, onde se pôde notar que a manutenção da população na região trata-se de uma expressão da resistência social local, na interface entre parâmetros ambientais e sociais analisados. A preservação da herança familiar (patrimonialismo) foi considerada o principal destaque nas narrativas dos sertanejos.

Palavras-chave: mobilização social; desertificação; neoextrativismo.

ABSTRACT: The analyzed region is historically a place of conflict and a 'founding violence', situated above São Francisco River, between the cities of Ibimirim and Cabrobó (Pernambuco/Brazil). The presence of those conflicts, associated with the environmental collapse, caused by the new local extractiv and arid climate, are strong evidence to act on population dynamics. However, the opposite is observed in the region. The maintenance of population there is supported by the low value of emigration and by narratives. Therefore, environmental and social variables were collected and analyzed to assess whether a social resistance motivates the lack of population dynamics. The objective of this study was to analyze the environmental context and the narratives of who remained in collapse of raw material in Arid Caatinga post the new extractivism. Where one might note that the maintenance of the population in the region is an expression of local social resistance, on the 
interface between the analyzed environmental and social parameters. The preservation of family heritage (patrimonialism) was considered the main highlight in the narratives of 'sertanejos'.

Keywords: social mobilization; desertification; new extractivism.

\section{Introdução}

A Caatinga é um ecossistema brasileiro, abrangendo cerca de $10 \%$ do território nacional (aproximadamente $850.000 \mathrm{~km}^{2}$ ), ocupando dez estados. É caracterizada por seus distrofismos: reduzida quantidade de água no sistema e baixa produtividade primária líquida (Sampaio et al., 2002; Silva et al., 2004). Por essa baixa produtividade primária, a flora e a fauna existentes são consumidas nos processos de demandas energéticas, o que causa processos de extinção e intensifica a desertificação do ambiente (Sampaio et al,. 2003; Sousa et al., 2012). O clima da região é caracterizado como Semiárido, com precipitações médias anuais abaixo de $1.000 \mathrm{~mm}$ e temperatura média anual acima de $27^{\circ} \mathrm{C}$ (BSh, segundo classificação climática de Köppen-Geiger), porém com regiões de Clima Árido, de precipitação anual menor que $250 \mathrm{~mm}$ e temperaturas médias anuais em torno de $33^{\circ} \mathrm{C}$ (BWh) (Peel; Finlayson \& McMahon, 2007). Associado a essa baixa concentração de carbono no sistema e ao extremismo climático, o desmatamento da Caatinga está acelerado. Além disso, esse ecossistema tem perdido aproximadamente 2.000 $\mathrm{km}^{2}$ por ano, sendo que $70 \%$ da vegetação já foi submetida a influências antrópicas (IBAMA, 2014).

Essas madeiras extraídas são utilizadas como matriz energética do Polo Gesseiro do Araripe (Microrregião de Araripina), que conta com 39 minas de gipsita, 139 indústrias de calcinação e cerca de 730 indústrias de pré-moldados, que utilizam essa madeira em $73 \%$ de sua matriz energética. $\mathrm{Na}$ região, a demanda anual de madeira foi estimada em 5,5 milhões de toneladas/ano (Serviço Florestal Brasileiro, 2013). Para produzir uma tonelada de gesso, se necessita utilizar $0,5 \mathrm{~m}^{3}$ de madeira nativa (Silva, 2009) ou 1,2 $\mathrm{m}^{3}$ de madeira reflorestada de eucalipto (Brainer et al., 2011).

Para uma produção sustentável de madeira, seria necessária uma área total de 155.000 hectares, com um ciclo de corte variando entre 10 e 15 anos. Porém, a Associação de Plantas do Nordeste (APNE, 2014) registra 94 planos de manejo florestais sustentáveis em Pernambuco, englobando uma área de 39.748 hectares, insuficientes para a demanda energética do Polo que cresce em 25\% ao ano, além das indústrias de cerâmicas $(\mathrm{CPRH}$, 2014). Como a correspondência em valores não se verifica, a extração ilegal de madeira da Caatinga é recorrente (Silva, 2009). Estudos demostraram que para uma espécie vegetal proveniente da Caatinga obter o volume de madeira e a sua densidade (propriedade física que lhe dá o poder calorífico) ideais para utilização industrial, demora em torno de 30 a 40 anos, provando, assim, que é insustentável essa prática de desenvolvimento para região (Aguiar $e t$ al., 2013).

Por isso, se registra que a Caatinga está no pós-neoextrativismo (Gudynas, 2012), principalmente a Caatinga Árida, pois, anacronicamente, cruzou a barreira da insustentabilidade, tanto ambiental como econômica. Esse neoextrativismo é definido como um modelo de desenvolvimento focado no crescimento econômico e baseado na apropriação de recursos naturais em redes produtivas pouco diversificadas, com a inserção subordinada na nova divisão internacional do trabalho (Milanez \& 
Santos, 2013). Ambientalmente, esse extrativismo devasta a flora e a fauna e altera o microclima, o que ocasiona uma insegurança alimentar e social na região, pois acelera o processo de desertificação, tornando-se difícil a manutenção de pequenas áreas ( $<3$ ha) pecuárias e de monoculturas.

Economicamente, a manutenção desse sistema gera lucros elevadíssimos no início, mas entra em colapso em curto prazo (Pindyck \& Rubinfeld, 2012), pois comete o erro de premissa da não sustentabilidade da matéria-prima, base para a produção (Weber, 2004). Alguns autores destacaram que a América Latina, e principalmente o Brasil, estão aderindo às práticas neoextrativistas (Milanez \& Santos, 2013), a tentar acompanhar o Produto Interno Bruto de países colapsados ambientalmente e com uma escravidão da classe trabalhadora (Willians, 2012). Armadilhas legais e econômicas são criadas (uso do solo e subsolo), que geram euforia inicial, porém com sequelas irreversíveis, como estratificação social, pobreza, processos de desertificação e tensões socioambientais (Gudynas, 2012).

A Caatinga Árida é o cenário ideal para o estudo dessas sequelas, pois se espera que, a partir do colapso causado pela extração dos recursos naturais, a população, principalmente a do campo, mais vulnerável ao clima e à desertificação, entre em um processo de migração em busca de alimento, habitação e trabalho. Esse refúgio, visto por décadas na região, fundamenta um dos imaginários sobre o "sertanejo retirante" como indivíduo na sociedade, fruto: i) do indivíduo socializado pelas disposições e hábitos; ii) do indivíduo orientado por instituições e normas sociais que o impõe; iii) do indivíduo que é reconhecido por suas relações sociais; e iv) do indivíduo que é construído por uma série de variáveis (Martuccelli \& Singly, 2012).

Porém, o que se observa é que há a manutenção da população no campo (em termos numéricos), resistindo à migração. Com isso, indaga-se se essa seria, então, uma resistência social. Resistência social, aqui, como a práxis política na qual um conjunto de indivíduos tenta empatar e, às vezes, superar as forças que querem dominá-los (hegemonicamente) (Chauí, 1986). Como também é possível questionar o que essa resistência influencia na significação social (Elias, 1965; Leontiev, 1978), na coesão social (Durkheim, 1967) e no tecido social (Suertegaray, 2001), e o que gera a resistência social (Muller, 2011) e a mobilização social (Touraine, 1978) frente ao colapso da matéria-prima. Com a tentativa de elencar elementos para direcionar a possíveis respostas a essas perguntas, o objetivo deste trabalho é analisar o contexto ambiental e a narrativa de quem ficou no colapso da matéria-prima, na Caatinga Árida pós-neoextrativismo.

\section{2. Área de Estudo}

A área de estudo corresponde à Zona Rural à margem das rodovias BR-360, BR-316 e BR-428, que se comunicam entre as cidades de Ibimirim e Cabrobó (Figura 1), em Pernambuco. A área total do estudo ocupa $872 \mathrm{~km}^{2}$ e compreende uma zona tampão (buffer zone) de $2 \mathrm{~km}$ à direita e à esquerda da rodovia, englobando, com isso, partes das localidades denominadas Caldeirão, Tabuleiro do Porco, Vila Grande, Airi, Espinheiro, Mulungu, Varjota, Malhada de Pedra, Ingazeira, Angico, Mocó e Pedra da Cuíca.

Este trecho da rodovia é destacado pelos registros de ocorrências na Polícia Rodoviária Federal e nas Delegacias do Munícipio de Ibimirim, Floresta e Cabrobó quinze vezes mais do que a média de outras rodovias em: i) interceptações e roubos de carros de passeio, ônibus, "carro forte" (carro de transporte de valores) e carga de abastecimento 


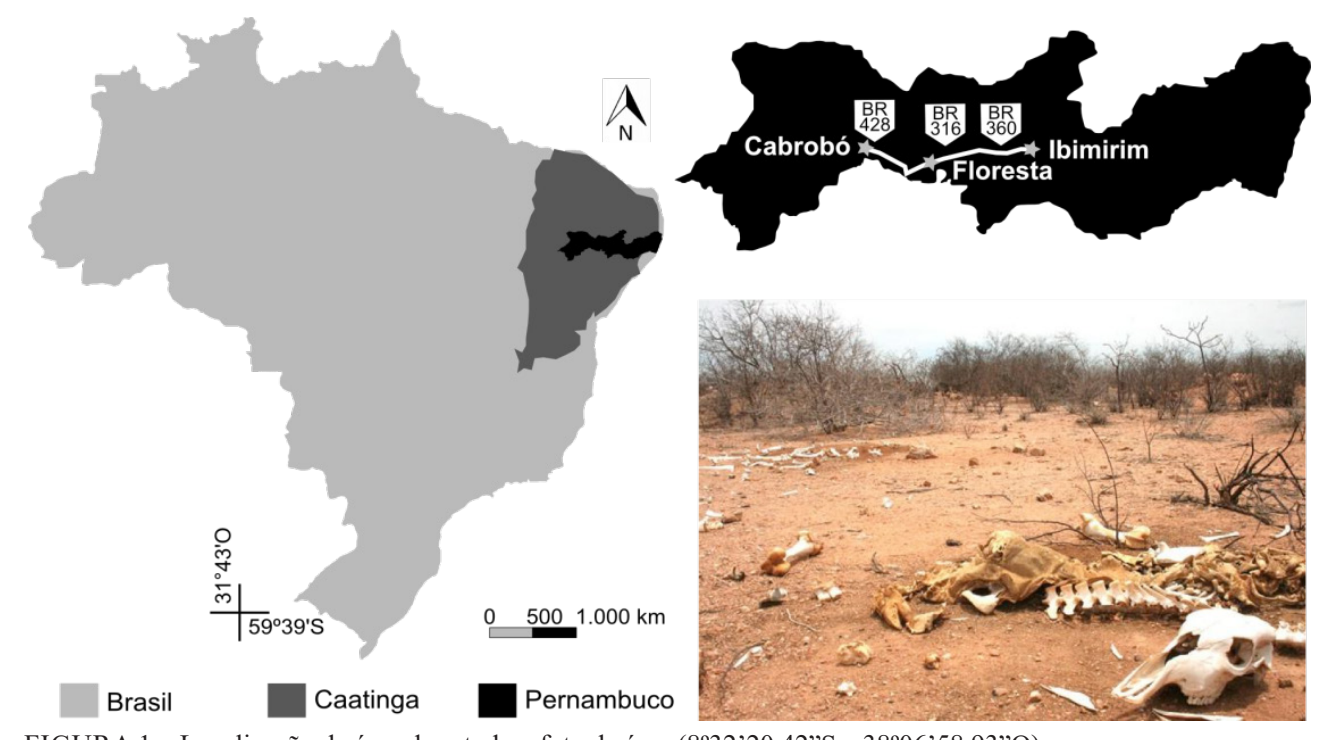

FIGURA 1 - Localização da área de estudo e foto da área (8³2’20.42”S e 3806'58.93”O).

(comida, produtos de limpeza, bebida, eletrodomésticos, eletrônicos, correios); ii) assassinatos, latrocínio e lesões corporais; e iii) tráfico de drogas e comércio ilegal de armas (Brasil, 1940). Em 2012, foram apreendidos $410 \mathrm{~kg}$ de maconha-Cannabis sativa L. Cannabaceae (G1/Pernambuco, 2012) e, em 2013, 209 kg em operações especiais realizadas pelo Departamento de Repressão ao Tráfico de Pernambuco (Denarc) (DPF, 2013) e $149 \mathrm{~kg} \mathrm{em}$ 2014 (BPM $8^{\circ}-$ PE, 2014).

\section{Métodos}

Os procedimentos para coleta dos dados e análise foram efetuados em duas fases que se integram: algumas variáveis do ambiente (abiótico e biótico) e as análises sociais a partir da narrativa, que permitiram emergir considerações sobre a interface objetivada: a resistência social (Figura 2). As variáveis ambientais foram principalmente as que destacaram o colapso da matéria-prima: água, flora e fauna, e as variáveis sociais foram as sensibilidades destacadas em nove abordagens (Figura 2), para todas darem suporte às análises da narrativa dos indivíduos que ainda permanecem in loco no período pós-neoextrativismo.

A construção de um metamétodo, aqui, justificava-se pela complexidade correlacional entre variáveis físico-ambientais (quantitativas) e variáveis humano-sociais (qualitativas), na perspectiva de uma resistência social. Não se intenciona, aqui, qualquer determinismo de causa ou efeito (positivismo). Com a utilização, então, de um plurimétodo, pode-se gerar evidências que, em algum espaço/ tempo na análise, convirjam-se (Hamlin, 2011). Para ir em direção a uma análise pós-estruturalista, a incursão estruturalista é necessária para poder caminhar nas fronteiras e nos limites do sujeito no habitat (oikos) e com seu habitus (sociedade): plurianálise (Teyssot, 1996). Apesar de nascerem de pontos epistemológicos distintos (análise das variáveis), tentou-se, aqui, superar os métodos e valorizar as evidências, mesmo que, para isso, algumas narrativas e análises se sustentem a partir 


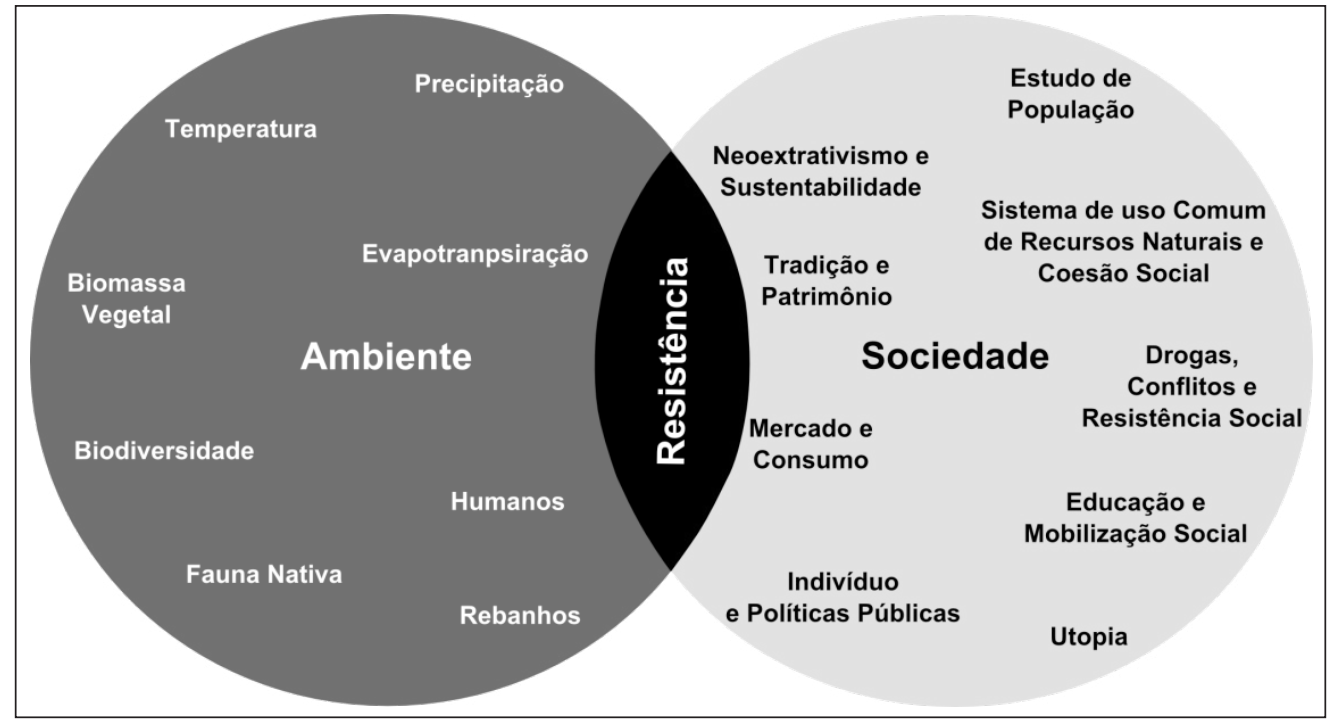

FIGURA 2 - Aspectos metodológicos avaliados para a área de estudo.

de autores predicados como críticos e pós-críticos (Wetherell, 1998).

As variáveis físicas: temperatura do ambiente, precipitação e evapotranspiração foram mensuradas em todos os anos de 2001, 2004, 2007, 2010 e 2013, por uma estação meteorológica modelo DRIA 0111 (Clima \& Ambiente, Cambuci, SP, Brasil), alocada em duas torres de $3 \mathrm{~m}$, situadas uma a $1 \mathrm{~km}$ acima ( $8^{\circ} 38^{\prime} 45,27^{\prime \prime}$ e e $38^{\circ} 43^{\prime} 48,80^{\prime \prime} \mathrm{O}$, SAD69) e outra a $1 \mathrm{~km}$ abaixo da rodovia $\left(8^{\circ} 41^{\prime} 57,74^{\prime \prime} \mathrm{S}\right.$ e 3849’38,97’O). A análise estatística de Regressão Linear foi efetuada entre os dados de temperatura $(y)$ e os anos analisados $(x)$ para cálculo do coeficiente de determinação, da equação, do erro e do nível de significância do ajuste. Verificaram-se as tendências da reta e as proporcionalidades utilizando o Programa BioEstat (Instituto Mamirauá, Tefé, AM, Brasil).

A biomassa vegetal $\left(\mathrm{Mg} \cdot \mathrm{ha}^{-1}\right)$ foi estimada segundo o Protocolo de Medições de Parcelas Permanentes da Rede de Manejo Florestal da Caatinga, e Rodal, Sampaio \& Figueiredo (1992), mensurada em 20 parcelas, de 50 por $50 \mathrm{~m}$, distribuídas uniformemente na área de estudo, na qual todos os indivíduos vegetais nas parcelas foram amostrados. A fauna levantada foi restringida aos grupos da mastofauna, da avifauna e da hepertofauna, sendo estimadas as espécies e a quantidade (Lazzaretti, 2013). Sob 20 transectos de $1 \mathrm{~km}$, também distribuídos de forma uniforme na área de estudo, foram alocadas 10 armadilhas do tipo Tomahawk (cinco) e Sherman (cinco). Nestes transectos, também foram realizados os métodos de interceptação e queda: 10 pitfall traps e duas redes de neblina. Além disso, foram realizados o método direto de observação, do registro de vestígios e, ao final, entrevistas de confirmação com a população.

Tanto a mensuração da flora quanto a mensuração da fauna foram realizadas a cada quadrimestre (janeiro, abril, agosto e dezembro) dos anos analisados: 2001, 2004, 2007, 2010 e 2013. A biodiversidade (flora e fauna) nos anos avaliados 
foi examinada pelo índice de diversidade Shannon (Shannon \& Weaver, 1949), calculado a partir do número de espécies e sua abundância ao final dos anos estudados. Uma análise não paramétrica $\chi^{2}$ (Qui-quadrado) foi efetuada para se calcular possíveis diferenças significativas $(p<0,05)$ entre os anos das variáveis biomassa vegetal, fauna nativa, cabeças de rebanhos e do índice de diversidade.

A população humana foi estimada a partir dos Censos do IBGE de 2000, 2007 e 2010 e da estimativa populacional de 2013, confirmados por meio dos registros de nascimento e mortalidade do cartório local. A imigração e a emigração foram certificadas pelas flutuações populacionais entre os dados do IBGE e dos registros em cartórios, também certificadas por meio de entrevistas, que coletaram as informações de escolaridade e classe etária. Uma análise não paramétrica $\chi^{2}$ (Qui-quadrado) foi efetuada para se calcular possíveis diferenças significativas $(p<0,05)$ entre: $i)$ a variação do número total de habitantes nos anos avaliados; ii) os dados de nascimento, mortalidade, imigração e emigração; e iii) os dados deste trabalho e os dados oficiais (IBGE, 2014; Index Mundi, 2014).

Juntamente às questões anteriormente postas nas entrevistas sobre informações da fauna (indagando-se qual espécie faunística, onde e o quantitativo observado) e dos dados populacionais de censo e migração (analisando quantas pessoas residem em sua moradia e quantas emigraram e imigraram, tais como escolaridade e classe etária), foram realizadas também as seguintes perguntas de resposta aberta: "O que faz você ficar aqui?", "O que te motiva a estar aqui?", "Você gosta daqui?", “Teve oportunidade de sair?", entre outras perguntas com mesmo princípio e voltadas ao entendimento da resistência social.

$\mathrm{Na}$ área de estudo, $10 \%$ das pessoas (92) foram entrevistadas, de janeiro a abril de 2014 , todas acima dos 18 anos. As respostas foram avaliadas de acordo com as principais démarches (respostas-chave Billouet, 2007) e analisadas segundo as narrativas descritivas e informativas (Scholes \& Kellogg, 1977; Gancho, 1991; Todorov, 2004). Essa análise foi associada às temáticas sociais apontadas (Figura 1). As perguntas feitas foram explicitadas em relação à compreensão linguística, caso algum morador não as compreendesse, e o mesmo foi feito no momento da transcrição das respostas. As entrevistas foram realizadas com um gravador de voz H2n (Zoom, Tokyo, Japão) e foram registrados os Termos de Consentimento Livre e Esclarecido (Registro UFPE: 112/00).

\section{Resultados das variáveis ambientais $e$ humanas}

Os dados climáticos certificaram a caracterização da área de estudo na Classificação de Köppen-Geiger de Clima Árido (BWh), conforme atualizado por Peel et al., (2007), pois há uma temperatura média anual acima $\operatorname{dos} 27^{\circ} \mathrm{C}$, com precipitação anual média abaixo dos $250 \mathrm{~mm}$ e com uma evapotranspiração maior que a precipitação (Figura 3). O que se observa, também, é que, ao passar dos anos analisados, houve uma tendência ao aumento da temperatura média anual, ou seja, há uma proporcionalidade direta e significativa $\left[R^{2}=0,71 ; p<0,001 ;\right.$ Erro $=0,017$; Temperatura $\left({ }^{\circ} \mathrm{C}\right)=0,33 \cdot($ Ano $)$ - 637,10] no aumento da temperatura ao passar dos anos.

Os registros quantitativos da biomassa vegetal nativa (Figura 4A), da pecuária (Figura 4B) e da fauna nativa (Figura $4 \mathrm{C}$ ) foram menores a cada ano avaliado, o que refletiu na redução da biodiversidade local, conforme notado pela redução do índice de diversidade de Shannon (Figura 4D). Em 2013, todos os resultados destas variáveis se aproximaram ao das regiões áridas, com a biomassa vegetal 


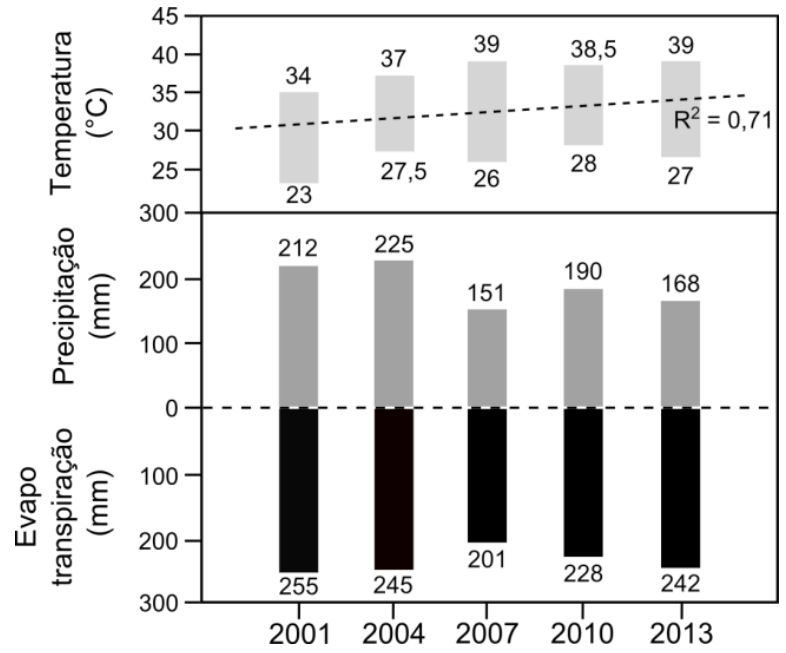

FIGURA 3 - Temperatura, precipitação e evapotranspiração mensurados na área de estudo. $\mathrm{R}^{2}=$ coeficiente de determinação da análise de regressão. abaixo de $2 \mathrm{Mg} \cdot$ ha $^{-1}$ (Cowlishaw \& Davies, 1997; Hegazy et al., 1998; Houérou, 1997; Abbadi et al., 2002; Enright et al., 2005; Hanafi, 2008; Bisigato et al., 2009; Vilela et al., 2009), com registros da fauna nativa (mastofauna, avifauna e hepertofauna) menores que 10 indivíduos por hectares (Wang et al., 2001; Scott et al., 2005; Ojeda \& Tabeni, 2009; Fokidis, 2011; Rodríguez \& Ojeda, 2011; McDonald, 2012; Herrmann \& Branch, 2013) e índices de diversidade de Shannon menores que 0,3 (Houérou, 1997; Kraaij \& Milton, 2006; Chillo \& Ojeda, 2012; Sow et al., 2014). Essas tendências dos dados também foram descritas em outras localidades áridas submetidas à perturbação antrópica, à mudança do uso da terra e ao extrativismo (Tabeni \& Ojeda, 2003, 2005; Reij et al., 2005; Sow et al., 2014).

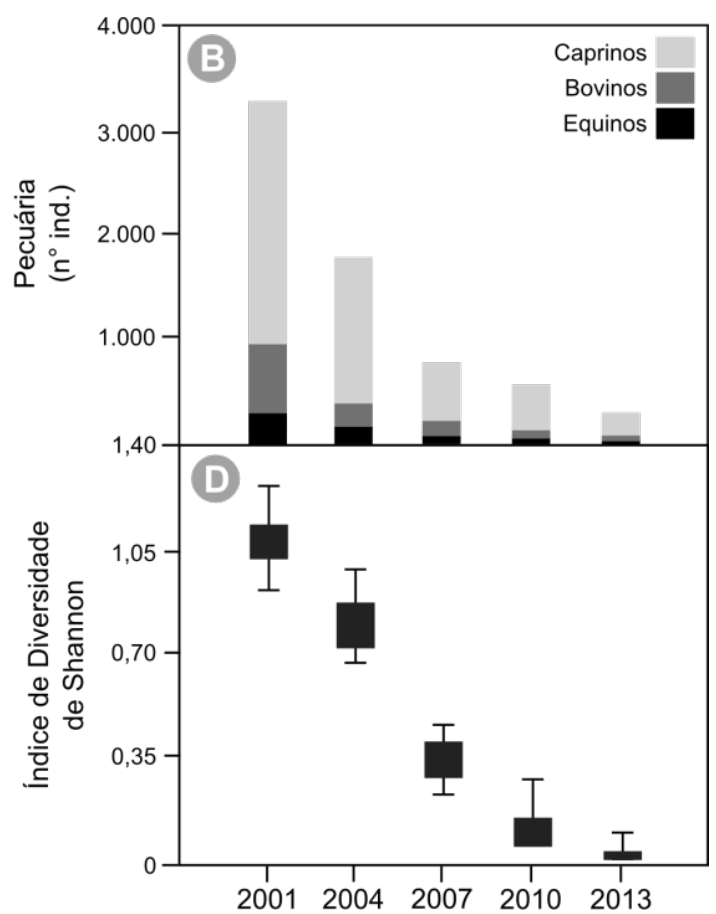

FIGURA 4 - Variação nos anos de estudo (2001, 2004, 2007, 2010 e 2013) da A) Biomassa Vegetal Nativa, da B) Pecuária, da C) Fauna Nativa, e o D) Índice de Diversidade de Shannon. Variação nas barras é desvio padrão. 
Já no Brasil, trabalhos alertaram sobre essas regiões que estão em processo de desertificação, causada pela mudança do uso da terra e intensificada pelas variações climáticas locais, não somente no ecossistema da Caatinga (Sampaio et al., 2003; Lima; Abreu \& Ferreira, 2008; Sampaio et al., 2008; Sousa et al., 2012), mas também na Região Amazônica (Oyama \& Nobre, 2003; 2004), no Cerrado (Ab'Sáber, 1977; Jackson et al., 2007) e nos Pampas (Overbeck, 2007). Nota-se que com a redução e a alteração do clima local, reduz-se, também, a pecuária em termos de cabeças no ambiente, não só de produção, como também de consumo local (Figura 4B), com o aumento da morte dos caprinos, bovinos e equinos remanescentes (Figura 4) (Castellano \& Valone, 2006; Hendricks et al., 2007; Goirán et al., 2012; Kong et al. 2014).

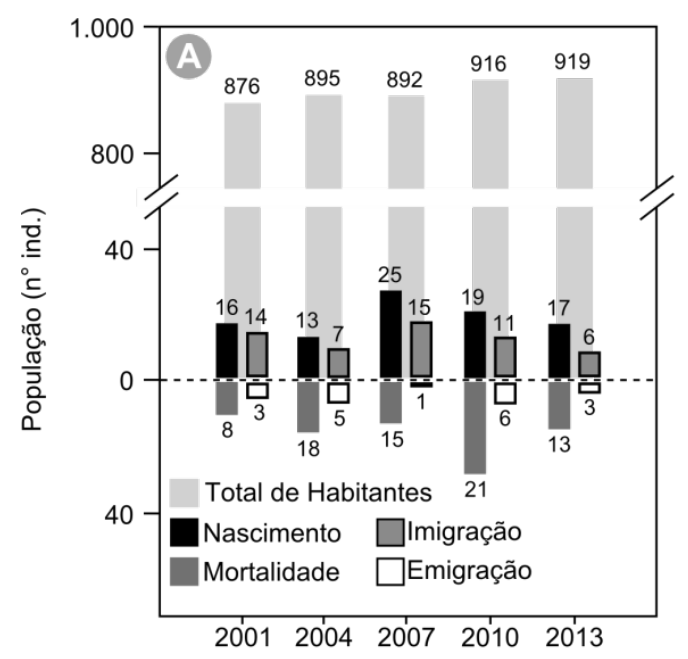

A redução de carbono biótico no ambiente e a redução da disponibilidade de água, vista pela maior taxa de evapotranspiração do que transpiração, motivam as dinâmicas populacionais humanas e se inicia, então, o processo de migração (Tacoli, 2009; Saier, 2010). Porém, isso não ocorreu na área de estudo. O número de habitantes se distribui de maneira equitativa estatisticamente no período estudado (Figura 5A), não havendo, assim, aumento ou redução significativa $(p=0,419)$, mesmo com variação no nascimento, na mortalidade, na imigração e na emigração.

Notou-se que o número médio de recém-nascidos nos anos avaliados foi de 20 por mil habitantes (por ano), próximo dos números oficiais de 17 por mil habitantes do Brasil (IBGE, 2014) e de países desérticos, como a Arábia Saudita, com
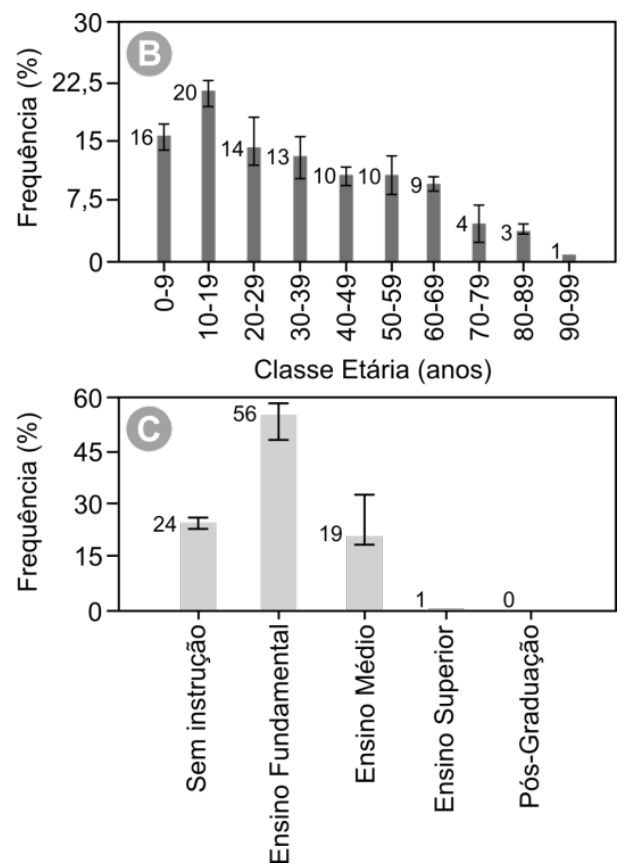

FIGURA 5 - A) População humana (Nascimento, Mortalidade, Imigração e Emigração); e dados de B) Classe Etária $(\mathrm{n}=919)$ e C) Escolaridade ( $=919)$, nos anos avaliados $(2001,2004,2007,2010$ e 2013). Variação nas barras é desvio padrão entre os anos de estudo. 
19 por mil habitantes (Index Mundi, 2014). Já o índice de mortalidade foi de 17 por mil habitantes, maior significativamente $(\mathrm{p}<0,001)$ do que o Brasil, com 6 (IBGE, 2014), e de 14 em países como a Somália, com elevado grau de desabastecimento (Index Mundi, 2014). Outro ponto de destaque é que, em média, a imigração $(10,6)$ superou a emigração $(3,6)$, dado observado principalmente em regiões de industrialização ou em suas adjacências (Baeninger, 2005).

Com isso, a análise das classes etárias seguiu o padrão brasileiro (IBGE, 2014), em que a maior parte $(50 \%)$ da população ficou distribuída nas classes etárias até 29 anos. Há, nesse ponto, uma estabilização entre as classes de 40 a 69 anos, distinta dos dados totais brasileiros, e uma redução acentuada a partir dos 70 anos (Figura 5B). Em termos de escolaridade (Figura $5 \mathrm{C}$ ), a região se distancia da média Nacional (IBGE, 2014) e notou-se que a maior parte (56\%) só concluiu o Ensino Fundamental; já nos dados totais brasileiros, os concluintes com apenas o Ensino Fundamental totalizam 10\%. Classificados como "Sem Instrução" foram 24\%, sendo que no Brasil apenas 9,3\% da população representam essa classificação. Os que concluíram o Ensino Médio e os que concluíram algum curso de graduação totalizaram em 19\% e $1 \%$, respectivamente, diferente do total na população brasileira, de $29,3 \%$ e $12,5 \%$, respectivamente.

\section{Narrativas e convergências}

As três primeiras démarches apontadas nas entrevistas foram a respeito do Clima e da Aridez:

O Clima aqui mudou, o que vi na infância não vejo mais. Chuva no dia de São José (19 de março) e geada no São João (24 de junho) não se vê mais. Banho de chuveiro, nunca tomei. (Entrevistado $\mathrm{n}^{\mathrm{o}} 18,56$ anos, agricultor, Região de Vila Grande, 02/02/2014).

Houve uma época que pegávamos muitos passarinhos nas armadilhas, mas poucos são vistos em nossa região. Outros animais desapareceram, foram consumidos ou embora daqui. Havia um pé de angico (Anadenanthera colubrina (Vell.) Brenan, Fabaceae), onde brincávamos e escutávamos vários cantos de pássaros. (Entrevistada $\mathrm{n}^{\circ}$ 47, 29 anos, estudante e agricultora, Região de Varjota, 04/03/2014).

Plantávamos feijão (Vigna unguiculata (L.) Walp., Fabaceae) e macaxeira (Manihot utilíssima Mill., Euphorbiaceae), hoje nem a palma forrageira dá para cultivar (Opuntia fícus-indica Mill., Cactaceae), assim como as espécies de madeira próprias da região como o juazeiro (Ziziphus joazeiro Mart.; Rhamnaceae), o umbuzeiro (Spondias tuberosa L., Anacardiaceae) e a aroeira (Lithraea molleoides (Vell) Engl, Anacardiaceae). O solo não aceita e a semente não vinga. (Entrevistado $\mathrm{n}^{\circ} 14,61$ anos, agricultor, Região de Tabuleiro de Porco, 28/01/2014).

Unanimemente, aparece nas transcrições dos 92 entrevistados a variação climática de um passado não distante, observada pelo relato de pessoas abaixo dos 30 anos de idade. Essa tendência foi corroborada (Figuras 3 e 4) por pesquisas que trabalharam com o imaginário, a memória e a cultura em regiões próximas, no Cariri Paraibano (Mariano Neto, 2001), e a vulnerabilidade socioambiental frente às mudanças no Semiárido Baiano (Santos, 2008), em que também se observam essas percepções.

Além disso, eventos climáticos que coincidiam com datas religiosas, como a chuva no dia de São José, não acontecem mais. A mudança do clima e a redução da prática agrícola na região, ocasionadas principalmente pelo insucesso das monoculturas frente à estiagem, foram relatadas por alguns autores, que destacam que culturas como a 
mandioca (Manihot esculenta Crantz, Euphorbiaceae) podem desaparecer da Caatinga. Por isso, a compensação ambiental por espécies nativas, que antes habitavam esta região, ficou insustentável, pois essas espécies já não conseguem sobreviver no microclima árido estabelecido (Zullo Jr.; Assad \& Pinto, 2008; Carvalho et al., 2013).

Outro destaque foi o modus vivendi para conseguir água e outras demandas:

Água, ou viajamos 15, 20 ou $30 \mathrm{~km}$ na Caatinga para pegar no Rio São Francisco, ou esperamos o Caminhão do Governo encher as cisternas. Às vezes, pela demora, compramos de caminhões-pipa particulares que passam pela região, vendendo dez mil litros de água por mil a dois mil reais (U\$ 450 a 900). Juntamos com os vizinhos para poder pagar por este recurso. Às vezes pagamos a água com animais ou objetos de valor que temos. A água é dividida com as cabras e bodes (Capra aegagrus hircus Lineu, Bovidae). (Entrevistado no 59, 26 anos, agricultor, Região de Malhada de Pedra, 16/03/2014).

Minha rotina é tentar cuidar dos animais e esperar o mensageiro. Compramos produtos e alimentos dos mensageiros. (Entrevistado ${ }^{\circ} 44,33$ anos, agricultor e pecuarista, Região de Mulungu, 01/03/2014).

Aágua utilizada para consumo é, em sua totalidade, obtida em outra região, conforme observado no relato anterior. Essa região foi beneficiada pelos Programas do Governo Federal "Programa Cisternas" (Ministério do Desenvolvimento Agrário, 2014), Programa “Água para Todos" e "Operação Carro-Pipa” (Ministério da Integração Nacional, 2014). Porém, como relatado, em alguns períodos, a população fica refém de comprar água de particulares, pois o caminhão-pipa de água nas metrópoles, como Recife, custa em torno de R\$500,00 ( $\approx$ U\$ 217,00) (Água Nova, 2014), ressaltando, assim, a exploração e o monopólio comercial.
Além disso, os "mensageiros" relatados na entrevista tratam-se do meio de transporte que circula pela região, basicamente de "Rural" (Toyota Bandeirante), na qual realizam o transporte de pessoas e fazem o serviço de correio, compras e transporte de valores, e, inclusive, sacam benefícios assistenciais do governo (e.g. Bolsa Família) nas zonas urbanas, a um preço de $10 \%$ por transação. Esse tipo de transporte é dado pela literatura como uma opção positiva, pois atua em locais onde as concessões e o governo não chegam. Porém, como atua sem nenhuma regulação, causa riscos aos passageiros pelo transporte fora dos padrões métricos de segurança e explora financeiramente a população, por não haver uma competição de mercado (Flores-Dueñas, 2004).

Sinais do neoextrativismo também foram relatados:

Vem caminhões aqui requisitando madeira a todo instante. Pagam $R \$ 2,00(\approx U \$ 0,90)$ o $\mathrm{m}^{3}$ de lenha, que vai para o Polo Gesseiro e para as Indústrias de Cerâmicas. As pessoas mais novas ( $<21$ anos) cedem a estas demandas por estarem constituindo familia e com filhos pequenos. Os mais velhos buscam a preservação. Mas não adianta, aqui o pobre preserva eo rico consome. (Entrevistado $\mathrm{n}^{\mathrm{0}} 77,55$ anos, agricultor, Região de Mocó, 04/04/2014).

A demanda pela lenha foi a principal causa da perda da Biomassa Vegetal (Figura 4). Para suprir uma demanda de madeira acima da oferta advinda das áreas de manejo sustentável da Caatinga, madeira ilegal é utilizada (Silva, 2009). É válido ressaltar que, de 30/05/2014 a 24/06/2014, a Agência Ambiental do Meio Ambiente de Pernambuco (CPRH, 2014) noticiou 17 atos de fiscalização, com notificações, advertências e apreensões de carga, corte ou utilização de madeira ilegal proveniente de espécies vegetais da Caatinga. 
O relato do entrevistado foi que as pessoas mais jovens acabam cedendo a essa prática de extração ilegal por ser a segunda opção de ganhar dinheiro na região, sendo a primeira o Programa Bolsa Família (Miranda, 2013).

Segundo esse próprio autor, esse programa assistencial no Semiárido está associado à redução da extração e da venda de madeira ilegal por populares às indústrias. Além disso, o desemprego massivo e episódico nessas regiões foi registrado e nota-se que há períodos com ausência total de trabalhadores registrados dentro do requerido pela Consolidação das Leis do Trabalho - CLT (Duarte, 2002). O valor da lenha também é destacado, pois as indústrias na região pagam de $\mathrm{R} \$ 12,00$ a 15,00 o $\mathrm{m}^{3}$ da lenha (estéreo) proveniente de madeiras certificadas (Brainer et al., 2011), o que mostra a defasagem do valor ambiental em um mercado paralelo.

Outro apontamento do entrevistado nesta démarche suscitou alguns enfoques, como qual o objetivo da preservação ambiental. Alguns autores já discutiram esse tema partindo do olhar de uma população economicamente de pouco poder de consumo, ou miserável, ou, ainda, famílias que vivem abaixo de um salário mínimo (DIEESE, 2014), ou, também, populações marginalizadas (índios, comunidades tradicionais, etc.). Primeiro, a aparência de que questões ambientais não são pautas dos marginalizados foi, assim, refutada. Outros autores certificaram que a pobreza não é um gerador da degradação ambiental no ambiente rural (Waquil et al., 2004) e que o sentimento de preservação ambiental perpassa classes econômicas e sociais (Bensusan, 2002). É válido lembrar que o processo de industrialização e a extração de matérias-primas foram os principais causadores da degradação ambiental no Brasil (Laurance et al., 2001; Sawyer, 2008).
Quanto à participação da família dita como pobre, indaga-se: "Qual a participação da mesma nos recursos no ambiente preservado?" Esse questionamento parece caminhar para o sentido do que ocorreu em zonas urbanas, em que ficou evidente a elitização do consumo dos recursos naturais em períodos extremos, visto o desabastecimento de água ocorrido em São Paulo, em 2014, em que bairros de classes econômicas elevadas (que recebem acima de 20 salários mínimos - DIEESE, 2014) continuaram a consumir este recurso sem interrupções ou reduções e que, em áreas pobres, acentuava-se o desabastecimento (Info, 2014).

Entretanto, o reconhecimento institucional e a construção de um indivíduo socializado, cidadania, além de suas disposições e hábitos, apareceram em períodos eleitorais, conforme observado no relato:

No periodo eleitoral, os candidatos nos buscam com caminhões e ônibus, somos beneficiados com roupas, alimentos, água e animais domésticos. Tiramos fotos e somos reconhecidos. (Entrevistado $\mathrm{n}^{\circ} 92,39$ anos, agricultor, Região de Pedra da Cuica, 19/04/2014).

Porém, esse reconhecimento, do singular para o individual, não reflete no sentido de autonomia política ativa (Martuccelli \& Singly, 2012) e nem de uma subjetivação política ativa (Touraine, 1978), e, sim, de uma objetivação utilitarista, em que o indivíduo deve considerar o bem-estar de todos e ir votar, como se o voto garantisse a total democracia (Mill, 1963).

Os motivos, então, para a fixação da população foram destacados nos próximos relatos:

Este pedaço de terra foi herança e não saio daqui por nada. Prometi a meu pai cuidar do que foi do meu avô e bisavô. Enterrei meus pais, minha avó e dois filhos aqui, embaixo de um umbuzeiro. Preservo este pedaço de chão com minha vida e minha alma. 
(Entrevistado n ${ }^{\circ} 29,47$ anos, agricultor e pecuarista, Região de Airi, 13/02/2014).

Há muito casamento entre primos aqui. Poucos arrumam mulheres e maridos de outras regiões. Pessoas de outras regiões são aquelas que vêm trabalhar por aqui e acabam ficando. (Entrevistada $\mathrm{n}^{\circ} 05,24$ anos, agricultora, Região de Caldeirão, 19/01/2014).

Nota-se que o papel da ancestralidade e da continuidade de permanência na terra perpassa o colapso ambiental. O apego ocorre em nome de uma família: patri (latim: pai) monium (latim: recebido). Esta manutenção familiar na terra é uma herança do período em que Pernambuco foi Capitania Hereditária (Assis, 2011). O patrimônio, portanto, é histórico, cultural e arquitetônico, porém não haverá um patrimônio ambiental (Figura 4), por toda exploração que ocorreu desde a colônia (Bueno, 1999).

Outro destaque é a pouca emigração $(<6$ pessoas por ano) na região, o que resulta em casamentos entre pessoas com grau de parentesco. Isto é importante, pois fortalece a indivisibilidade de heranças, no caso das terras (Camarote, 2011). Um possível fracionamento da propriedade, em quinhões, causaria a redução do tamanho da terra a ser extraída (neoextrativismo) e de produção agropecuária, e enfraqueceria o valor patrimonial (Galizoni, 2002).

Além disso, a delimitação da propriedade, somada a esse patrimonialismo, resulta no que alguns autores retratam como territorialidade étnica (etnocentrismo), observada pelas análises históricas, tratando-se, assim, de uma referência identitária do sertanejo (a defesa da "honra"), no caso, da sertanidade: a defesa do patrimônio (terra) (Oliveira, 2011). E nessa mesma análise histórica, a sertanidade possui um estigma regional, narrado de uma "violência fundadora": i) da colonização do sertão (séc. XVII), com extermínio e escravização de índios e o estabelecimento dos canaviais; ii) da substituição do gentio pela pecuária (séc. XVIII); iii) pelo coronelismo, disputas familiares e confrontos indígenas (séc. XIX); iv) pelo "eixo político familiar" (oligárquico) e cangaço (séc. XX); e, iv) pela consolidação do "Polígono da Maconha" e do tráfico (séc. XXI) (Abreu, 1960; Alencastro, 2000; Martins, 2008; Oliveira, 2011; Fraga \& Iulianelli, 2011; Fraga, 2012; Oliveira, 2012).

A consolidação deste último se deu a partir da crise algodoeira nas regiões semiáridas, próximas ao Rio São Francisco, onde emergiram as plantações de maconha a partir da década de 80 (séc. XX). Como não há uma regulação para o plantio, houve uma crescente atividade ilegal na área, envolvendo: i) guerras por propriedades de terra e pelo comércio; ii) trabalho escravo; iii) formação de milícias especializadas (jagunços, cabras e capangas); iv) expulsão do trabalhador do campo e pequenos produtores rurais; e v) controle viário da região, acentuando assim o conflito rural (Fraga \& Iulianelli, 2011). Somado a isso, a partir da década de 90 (séc. XX), houve um recrudescimento da economia antidrogas pela atuação na área da Companhia Independente de Operações e Sobrevivência na Área da Caatinga (CIOSAC), que se trata de uma força policial especializada, e também da presença das polícias federal e estadual (Oliveira, 2011; 2012).

Essa instabilidade local na região do Submédio do Rio São Francisco fez com que houvesse uma migração da população para regiões da Caatinga Árida, área deste trabalho, regiões essas onde não se planta maconha, devido ao extremismo climático, o que ocasiona conflitos por propriedades rurais $\mathrm{e}$ por recursos naturais, além da disputa pelas vias e rodovias para escoamento do tráfico (Fraga, 2012). 
A preocupação de invasões às propriedades e os conflitos foram destacados nos relatos:

Há um bando que ameaça constantemente por aqui, fazem um terrorismo, fecham as estradas e constantemente vemos carros abandonados e queimados, $e$ corpos de pessoas mortas, ao longo da rodovia. A intenção é que abandonemos aqui, facilitando a comunicação, o domínio das estradas, entre o Rio São Francisco e a rodovia (BR428, BR316 e BR360). Não conseguiria viver em outra região e ver outra pessoa morando em nossa terra. Ficaria muito triste ver bandidos invadindo aqui. (Entrevistada $\mathrm{n}^{\mathrm{o}} 31,47$ anos, agricultora, Povoado de Espinheiro, 13/02/2014).

Nessa sistemática para permanecerem na terra, acabam por transparecer uma resistência social. A comunidade da área de estudo possui uma identidade (sertanidade), um sistema antagônico a ser vencido (as milícias e refugiados do "Polígono da Maconha") e um projeto em comum (manterem suas propriedades: patrimônio), sendo, assim, requisitos para a mobilização e resistência social local (Scherer-Warren, 2006; 2007). Observa-se, também, que há um conflito, no qual uma parte social se sente ameaçada contra seus os valores, status, poder e recursos, e, assim, tenta neutralizar ou eliminar seus adversários (Simmel, 1992; Coser, 2009).

Verifica-se que a colônia, os coronéis, algumas famílias e o cangaço sempre atentaram a uma sertanidade pacífica e harmoniosa da Caatinga Árida, desde o séc. XVI (Bueno, 1999), a transcender, então, a figura individual e coletiva de resistência (Coser, 2009), na qual opera sobre a propriedade da terra. Para isso, a comunidade se une para a aquisição de recursos naturais e produtos (e.g. água), conforme observado na transcrição anterior do Entrevistado 59, e de como se mobilizam para o combate a ameaças e possível usurpação:
Quando somos ameaçados, roubados, ou se há uma quebra de cerca, juntamos com os vizinhos (aproximadamente 11 famílias na região) e, de forma pacifica, vamos até a propriedade vulnerável e dormimos lá, até que se resolva a situação ou que volte a paz. Se pegamos algum suspeito, levamos às Delegacias das cidades próximas. (Entrevistado $\mathrm{n}^{\circ} 38,47$ anos, agricultor e pecuarista, Região de Mulungu, 22/02/2014).

Se surgem novas estradas avulsas, tratamos logo de impedi-las com pedras e avisamos as policias. Fazemos rondas de moto pelas propriedades e estradas, mas não andamos armados. A polícia investe pouco aqui, pois quando aparecem, há confrontos com as milicias, principalmente nas rodovias. (Entrevistado $n^{\circ}$ 67, 47 anos, pecuarista, Região de Angico, 24/03/2014).

Estes relatos também exaltam a coesão social observada, pelo grau de consenso entre os membros do grupo social (sertanidade), do qual se pode observar a ação social (Durkheim, 1967) frente aos grupos invasores. E, nessa Caatinga Árida, atores sociais produzem um sentido dentro de um universo simbólico: defesa do patrimônio (interacionismo simbólico) (Blumer, 1986), também percebido por uma amálgama de apego ambiental e sentimental à terra: topofilia (Tuan, 1974). Isso envolve desde a cultura até o significado da resistência em se manter na região: tecido social (Suertegaray, 2001).

Essa topofilia, no sentido da antropologia social, é o apego que vincula sensivelmente pessoas ao ambiente natural ou construído por aspectos subjetivos e concretos, como: i) o ambiente físico no imaginário social; ii) a relação entre paisagem, memória e cultura; iii) a experiência individual e a visão de mundo que constroem identificações, compartilhadas em um território comum; e iv) ao espiritual e religioso que o ambiente emerge (Tuan, 1974). É observada, também, a autorregulação, ou 
seja, a ordem é estabelecida e definida pelas instâncias de razão social (funcionalismo) (Parsons, 1951), a eliminar correntes ilegais geradas pelo "Polígono da Maconha", pois os confrontos são frequentes nessa área.

A literatura destaca que nessa região, em 15 anos (1995-2009), mais de 100 pessoas morreram em confrontos com as milícias advindas de áreas de proteção e tráfico da maconha (Barbosa, 2009). Outra pesquisa indicou que a região poderia estar atrelada a ramificações com grupos criminosos do Comando Vermelho, do Rio de Janeiro, devido à prisão do traficante carioca "Ostinho do Fubá", em Salgueiro (Fraga, 2012). Além do mais, Floresta (PE) chegou a ser uma das cidades mais violentas do país, na posição $135^{\circ}$, com taxa de homicídio de 54 mortes por 100 mil habitantes (por ano), superior à média nacional, de 27 mortes por 100 mil habitantes (Consejo Ciudadano para la Seguridad Pública y Justicia Penal AC, 2013).

Algumas transcrições de relatos sobre esses conflitos emergem e, quando há uma organização das famílias e a construção de possíveis lideranças, começam a aparecer, também, ameaças de morte a essas forças e lideranças, a requerer que essas organizações mudem dali. Tática essa já conhecida para pulverização de mobilizações e resistências sociais (Revkin, 2004; Fearnside, 2006; Bob \& Nepstad, 2007), porém que não gera efeitos a longo prazo.

Em pesquisa realizada se concluiu que assassinar um líder não significa acabar com um movimento social (Bob \& Nepstad, 2007). Um destes relatos foi:

Aqui na região quando chega alguma liderança religiosa, sindical ou mesmo que aflore dos populares, há logo ameaças duras contra esta pessoa. Temem uma organização nossa, ou um movimento político ou conscientização crítica. Há uma preocupação com eventos religiosos aqui, pensam que estamos nos agregando para fazermos alguma "frente". (Entrevistada $\mathrm{n}^{\circ}$ 62, 74 anos, benzedeira e parteira, Região de Ingazeira, 19/03/2014).

Portanto, uma das alternativas para o fortalecimento de um movimento social e sua manutenção é o investimento em educação e todo o espírito crítico e libertador (Freire, 1996). Essa educação fundamentará a posição tomada, guiará para um conflito que dispenda o mínimo de energia possível e fará com que o projeto comum seja implementado e estabelecido (Vendramini, 2007). Porém, a educação é vista como segregadora pelos mais antigos, pois os jovens que estudam partem para outras cidades, esvaziando o projeto patrimonialista local:

\begin{abstract}
A Educação é o único fator que leva as pessoas embora daqui. Sinto feliz por ver minha filha estudando, mas preocupado, pois, sei que ela vai embora, e aqui ficará abandonado quando morrer. Os filhos têm que ficar do lado dos pais, cuidar dos pais. Não deve sair daqui. Tudo o que fiz foi pensando neles e o que preservei foi para deixar para eles. (Entrevistado $\mathrm{n}^{\circ}$ 22, 96 anos, agricultor e pecuarista, Região de Airi, 06/02/2014).
\end{abstract}

A maioria dos entrevistados (89 de 92) também certificou que, além dos conflitos, da tensão e da violência, existe um sentimento de transcendência pelo ambiente (topofilia novamente) e pelo qual não querem sair da Caatinga Árida, mesmo vivendo em um anacronismo, sem a inserção em uma sociedade pós-moderna cosmopolita. Essas pessoas marcadas pelas atitudes e valores emergidos por anos de resistência social e resistência fisiológica ambiental criaram essa sertanidade, sendo, portanto, um povo marcado por lutas (Oliveira, 2012).

Porém, nessas mesmas pessoas fica evidente o sentimento utópico, do tipo progressista (More, 1989). Elas denotaram que o "local ideal" é ali, mas 
que um tempo "melhor" virá e que não ficou no passado, como descreveram os nostálgicos (Boym, 2001). Isso devido, possivelmente, ao histórico de exploração natural e social na região, relatado na transcrição abaixo:

Gosto muito daqui e vai melhorar, um dia choverá, e produziremos as roças e os rebanhos, e a fauna e flora nativa habitarão aqui, por isso não vou embora. (Entrevistada $n^{\circ} 34,43$ anos, agricultora, Região de Espinheiro, 18/02/2014).

Contudo, as narrativas registradas e analisadas exaltaram: i) a sobrevivência da população frente ao clima e a aridez; ii) a percepção da mudança climática; iii) o neoextrativismo e a exploração de quem extrai; iv) o esgotamento da fauna e da flora nativa; v) a dificuldade da aquisição de água e de manter plantações e rebanhos; vi) a presença política apenas no período eleitoral; vii) a herança e o patrimonialismo; viii) a tensão, as resistências, a mobilização e os conflitos entre os transeuntes; ix) a ameaça e a desarticulação de lideranças e mobilizações sociais; $x$ ) a educação como desintegradora do patrimonialismo; e xi) a topofilia e a utopia progressista. Esses tópicos levantados sintetizaram as características do povo da região, a sertanidade, pois ressaltam que o processo humano está fundado em uma luta para o reconhecimento (Hegel, 1807) e que, no estado da natureza, o conflito cessa somente com a morte (Hobbes, 1840).

\section{Considerações finais}

A região estudada, Caatinga adjacente à rodovia entre Ibimirim e Cabrobó (Pernambuco), está colapsada ambientalmente pela extração de madeira para as indústrias gesseiras e de cerâmicas, como também está economicamente insustentável (pós- -extrativismo). Essa região é marcada socialmente por tensões e conflitos históricos, desde a colonização (séc. XVII) a correntes rotas do tráfico (séc. $\mathrm{XXI}$ ), pois o plurimétodo e a plurianálise utilizados permitiram emergir evidências que se convergiram ao longo do texto.

Além disso, os resultados das variáveis físico-ambientais suscitaram a tendência à aridez da região estudada na Caatinga e a progressiva redução da biodiversidade no período avaliado, a se assemelhar a outras regiões áridas do planeta. Observou-se que a dinâmica populacional se manteve estática, ou seja, não houve uma flutuação significativa na emigração e na imigração, no nascimento e na mortalidade, a qual indique que o número de habitantes esteja a reduzir ou aumentar em resposta à extremidade do clima ou à escassez ambiental de recursos primários.

As narrativas também evidenciaram as tendências dos dados ambientais e os motivos da manutenção da população na região, pois a ausência da migração trata-se de uma expressão da resistência social local na interface entre os parâmetros ambientais e sociais analisados. Além disso, a preservação da herança familiar (patrimonialismo) foi o principal destaque nas narrativas do sertanejo, tanto no colapso da matéria-prima quanto nos conflitos passados, presentes e futuros, se houver.

\section{Agradecimentos}

Ao grupo de pesquisa "Educometria" (DBR/ $\mathrm{CB} / \mathrm{UFPE}$ ) pelo suporte na coleta e interpretação dos dados, e a Pró-Reitoria de Extensão e Cultura da Universidade Federal de Pernambuco (PROE$\mathrm{xC} / \mathrm{UFPE}$ ) pelo apoio financeiro (Editais PIBEX/ UFPE). 


\section{Referências}

Abbadi, G.; Mohamad, A.; El-Sheikh, A. Vegetation analysis of Failaka Island (Kuwait). Journal of Arid Environments, 50, 153-165, 2002. doi: 10.1006/jare.2001.0855

Abreu, J. C. de. Caminhos antigos e povoamento do Brasil. 2. ed. Rio de Janeiro: Sociedade Capistrano de Abreu, Livraria Briguiet, 1960.

Ab'Sáber, A. N. Problemática da desertificação e da savanização no Brasil intertropical. São Paulo: Instituto de Geografia da USP, 1977.

Água Nova. Venda de água através de caminhão-pipa. Disponível em: <http://www.aguanovaonline.com.br/> Acesso em: jan. 2014.

Aguiar, M. M. B.; Santana, O. A.; Inácio, E. S. B.; Amorim, L. B.; Almeida-Cortez, J. S. Tree resilience after clearcutting in sustainable forest management of semi-arids areas. In: Annals of 2nd United Nations Convention to Combat Desertification Scientific Conference, 2013, Bonn. 2nd UNCCD. 2nd: UNCCD, 2013.

Alencastro, L. F. O trato dos viventes: formação do Brasil no Atlântico Sul. São Paulo: Companhia das Letras, 2000.

APNE - Associação de Plantas do Nordeste. Centro Nordestino de Informações sobre Plantas. Planos de Manejo Sustentáveis da Caatinga. Disponível em: <http://www. cnip.org.br/>. Acesso em: jan. 2014.

Assis, V. M. A. Ofícios do rei: a circulação de homens e ideias na capitania de Pernambuco. In: Roberto Guedes. (Org.). Dinâmica imperial no antigo regime português: escravidão, governos, fronteiras, poderes, legados (Séculos XVII-XIX). Rio de Janeiro: Mauad X, 2011.

Baeninger, R. São Paulo e suas migrações no final do século 20. São Paulo em perspectiva, 19, 84-96, 2005.

Barbosa, F. J. Evolução do banditismo moderno e formas de atuação eficazes da policia militar no sertão pernambucano. 78f., il. Olinda, Trabalho de Conclusão de Curso (Pós-graduação em Gestão da Segurança Pública na Sociedade Democrática) - ULBRA/PRONASCI, 2009.

Bensusan, N. (Org.). Seria melhor mandar ladrilhar? Biodiversidade, como, para que, por quê. 1. ed. Brasília: Editora Universidade de Brasília, 2002.
Billouet, P. (Org.). Débattre: Pratiques scolaires et démarches éducatives. Paris: L'Harmattan. 2007.

Bisigato, A. J.; Villagra, P. E.; Ares, J. O.; Rossi, B. E. Vegetation heterogeneity in Monte Desert ecosystems: A multi-scale approach linking patterns and processes. Journal of Arid Environments, 73, 182-191, 2009. doi: 10.1016/j. jaridenv.2008.09.001

Blumer, H. Symbolic Interactionism: Perspective and Method. Berkeley: University of California Press, 1986.

Bob, C.; Nepstad, S. E. Kill a leader, murder a movement? Leadership and assassination in social movements. American Behavioral Scientist, 50, 1370-1394, 2007. doi: 10.1177/0002764207300162

Boym, S. The Future of Nostalgia. New York: Basic Books, 2001.

BPM $8^{\circ}$ - Batalhão da Polícia Militar de Pernambuco. Policia Militar apreende $149 \mathrm{~kg}$ de maconha pronta para o consumo em Salgueiro - 19/06/2014. Disponível em: $<$ http://www.pm.pe.gov.br/>. Acesso em: jun. 2014.

Brainer, M. S. C. P.; Vidal, M. F.; Ferreira, O. P.; Nahuz, M. A. R. Manejo Florestal: uma possibilidade de parceria entre calcinadores e apicultores na Chapada do Araripe (PE). Informe Rural Etene, Banco do Nordeste, 5, 1-17, 2011.

Brasil. Código Penal Brasileiro. Decreto-Lei no 2.848 , de 7 de dezembro de 1940. Disponível em: <http://www. planalto.gov.br/ccivil_03/decreto-lei/del2848.htm>.Acesso em: fev. 2014.

Bueno, E. Capitães do Brasil: a saga dos primeiros colonizadores. Rio de Janeiro: Objetiva, 1999.

Camarote, E. M. Territorialização e parentesco em uma comunidade baiana de fundo de pasto. Ruris, 5, 121-153, 2011.

Carvalho, J. R. P.; Assad, E. D.; Pinto, H. S. Estimation of dry spells in three Brazilian regions - Analysis of extremes. Atmospheric Research, 132-133, 12-21, 2013. doi: 10.1016/j.atmosres.2013.04.003

Castellano, M. J.; Valone, T. J. Effects of livestock removal and perennial grass recovery on the lizards of a desertified arid grassland. Journal of Arid Environments, 66, 87-95, 2006. doi: 10.1016/j.jaridenv.2005.10.016 
Chauí, M. S. Conformismo e resistência: aspectos da cultura popular no Brasil. São Paulo: Brasiliense, 1986. 179 p.

Chillo, V.; Ojeda, R. A. Mammal functional diversity loss under human-induced disturbances in arid lands. Journal of Arid Environments, 87, 95-102, 2012. doi: 10.1016/j. jaridenv.2012.06.016

Consejo Ciudadano para la Seguridad Pública y Justicia Penal AC. Raking Violento. Disponível em: < http://www. seguridadjusticiaypaz.org.mx/>. Acesso em: dez. 2013.

Coser, L. A. Theorie sozialer Konflikte. Berlin: Springer, 2009. 195 p.

Cowlishaw, G.; Davies, J. G. Flora of the Pro-Namib Desert Swakop River Catchment, Namibia: community classification and implications for desert vegetation sampling. Journal of Arid Environments, 36, 271-290, 1997. doi: 10.1006/jare.1996.0203

CPRH - Agência Ambiental do Meio Ambiente de Pernambuco. Madeira ilegal-Buscas. Disponível em: $<$ http:// www.cprh.pe.gov.br/Resultados.asp?page $=2 \&$ texto $=$ MADEIRA\%20ILEGAL>. Acesso em: jun. 2014.

DIEESE - Departamento Intersindical de Estatística e Estudos Socioeconômicos. Classificação social por salários mínimos. Disponível em: <http://www.dieese.org.br/>. Acesso em: jun. 2014.

DPF - Departamento da Polícia Federal. PF faz maior apreensão de maconha dos últimos 5 anos da região 13/04/2013. Disponível em: <http://goo.gl/YiHltn>. Acesso em: jun. 2014.

Duarte, R. Um tipo singular de desemprego massivo e episódico: o caso dos flagelados das secas no Semiárido Nordestino. Revista da ABET, 2, 119-120, 2002.

Durkheim, E. De la division du travail social. Paris: P.U.F., 1967.

Elias, N. The Established and the Outsiders. A Sociological Enquiry into Community Problems. Londres: Frank Cass \& Co., 1965.

Enright, N. J.; Miller, B. P.; Akhter, R. Desert vegetation and vegetation-environment relationships in Kirthar National Park, Sindh, Pakistan. Journal of Arid Environments, 61, 397-418, 2005. doi: 10.1016/j.jaridenv.2004.09.009

Fearnside, P. M. Desmatamento na Amazônia: dinâmica, impactos e controle. Acta Amazônica, 36, 395-400, 2006.
Flores-Duenãs, M. A. Competição e regulação no transporte de passageiros: um estudo no transporte rodoviário intermunicipal. 185f., il. Natal, Dissertação (Mestrado em Engenharia de Produção) - Universidade Federal do Rio Grande do Norte, 2004.

Fokidis, H. B. Homeowners associations: Friend or foe to native desert avifauna? Conservation concerns and opportunities for research. Journal of Arid Environments, 75, 394-396, 2011. doi: 10.1016/j.jaridenv.2010.12.003

Fraga, P. C. P. Plantaciones ilícitas como fuente de ingresos alternativa y expresión de desigualdad: el caso del cultivo de cannabis en el nordeste de Brasil. Estudios Sociológicos, 30, 143-169, 2012.

Fraga, P. C. P.; Iulianelli, J. A. S. Plantios ilícitos de cannabis no Brasil: desigualdades, alternativa de renda e cultivo de compensação. Dilemas: Revista de Estudos de Conflito e Controle Social, 4, 11-39, 2011.

Freire, P. Pedagogia do oprimido. São Paulo: Paz e Terra, 1996.

Galizoni, F. M. Terra, ambiente e herança no alto Jequitinhonha, Minas Gerais. Revista de Economia e Sociologia Rural, 40, 77-96, 2002. doi: 10.1590/S0103-20032002000300003

Gancho, C. V. Como analisar narrativas. São Paulo: Ática, 1991.

Goirán, S. B.; Aranibar, J. N.; Gomez, M. L. Heterogeneous spatial distribution of traditional livestock settlements and their effects on vegetation cover in arid groundwater coupled ecosystems in the Monte Desert (Argentina). Journal of Arid Environments, 87, 188-197, 2012. doi: 10.1016/j. jaridenv.2012.07.011

Gudynas, E. Estado compensador y nuevos extractivismos. Nueva Sociedad, 237, 128-146, 2012.

G1/Pernambuco - Globo Nordeste. Apreensão recorde encontra mais de $400 \mathrm{~kg}$ de maconha - 17/09/2012. Disponível em: <http://goo.gl/7IUVuR>. Acesso em: jun. 2014.

Hamlin, C. L. Breve metametodologia das Ciências Sociais. Revista Latinoamericana de Metodología de la Investigación Social, 1, 8-20, 2011.

Hanafi, A. Are long-term vegetation dynamics useful in monitoring and assessing desertification processes in the arid steppe, southern Tunisia. Journal of Arid Environments, 72, 557-572, 2008. 
Hegazy, A. K.; El-Demerdash, M. A.; Hosni, H. A. Vegetation, species diversity and floristic relations along an altitudinal gradient in south-west Saudi Arabia. Journal of Arid Environments, 38, 3-13, 1998. doi: 10.1006/jare.1997.0311

Hegel, G. W. F. Naturphilosophie. Sttutgart: Bamberg, 1807.

Hendricks, H. H.; Bond, W. J.; Midgley, J. J.; Novellie, P. A. Biodiversity conservation and pastoralism - reducing herd size in a communal livestock production system in Richtersveld National Park. Journal of Arid Environments, 70, 718-727, 2007. doi:10.1016/j.jaridenv.2006.12.023

Herrmann, H. W.; Branch, W. R. Fifty years of herpetological research in the Namib Desert and Namibia with an updated and annotated species checklist. Journal of Arid Environments, 93, 94-115, 2013. doi:10.1016/j.jaridenv.2012.05.003

Hobbes, T. Human Nature: Or The Fundamental Elements of Policy Bound with De Corpore Politico. Or the Elements of Law. Bristol: Thoemmes Press, 1840.

Houérou, H. N. L. Climate, flora and fauna changes in the Sahara over the past 500 million years. Journal of Arid Environments, 37, 619-647, 1997. doi: 10.1006/jare.1997.0315

IBAMA - Instituto Brasileiro do Meio Ambiente e dos Recursos Naturais Renováveis. 2014. Sistema Compartilhado de Informações Ambientais. Disponível em: <http://siscom. ibama.gov.br/>. Acesso em: jan. 2014.

IBGE - Instituto Brasileiro de Geografia e Estatística. Estados@. Disponível em:<www.ibge.gov.br/estadosat/>. Acesso em: maio 2014.

Index Mundi. Trade Statistics. Disponível em: <http:// indexmundi.com>. Acesso em: maio 2014.

Info. Falta água em bairros de SP; Sabesp nega racionamento - 15/05/2014. Disponível em: <http://info.abril. com.br/noticias/tecnologias-verdes/2014/05/falta-agua-em-bairros-de-sp-sabesp-nega-racionamento.shtml>. Acesso em: jun. 2014.

Jackson, R. B.; Farley, K. A.; Hoffmann, W. A.; Jobbágy, E. G.; McCulley, R. L. Carbon and water tradeoffs in conversions to forests and shrublands. In: Terrestrial Ecosystems in a Changing World. Heidelberg: Springer, 2007. p. 237-246.

Kong, T. M.; Austin, D. E.; Kellner, K.; Orr, B. J. The interplay of knowledge, attitude and practice of livestock farmers' land management against desertification in the South African Kalahari. Journal of Arid Environments, 105, 12-21, 2014. doi: 10.1016/j.jaridenv.2014.02.002

Kraaij, T.; Milton, S. J. Vegetation changes (1995-2004) in semi-arid Karoo shrubland, South Africa: Effects of rainfall, wild herbivores and change in land use. Journal of Arid Environments, 64, 174-192, 2006. doi: 10.1016/j. jaridenv.2005.04.009

Laurance, W. F.; Cochrane, M. A.; Bergen, S.; Fearnside, P. M.; Delamônica, P.; Barber, C.; D’Angelo, S.; Fernandes, T. Environment: the future of the Brazilian Amazon. Science, 291, 438-439, 2001. doi: 10.1126/science.291.5503.438

Lazzaretti, T. Métodos de pesquisa para levantamento da fauna silvestre: teoria \& prática. Xanxerê: Energyx, 2013.

Leontiev, A. O desenvolvimento do psiquismo. Lisboa: Horizonte Universitário, 1978.

Lima, F.; Abreu, R. F.; Ferreira, L. Relações solo-vegetação em áreas sob processo de desertificação no município de Jataúba, PE. Revista Brasileira de Ciência do Solo, 32, 1283 1296, 2008. doi: 10.1590/S0100-06832008000300036

Mariano Neto, B. Ecologia e imaginário: memória cultural, natureza e submundialização. 1. ed. João Pessoa/PB: Editora Universitária/UFPB, 2001.

Martins, M. D. Açúcar no sertão: a ofensiva capitalista no Nordeste do Brasil. São Paulo: Annablume, 2008.

Martuccelli, D.; Singly, F. Las sociologías del individuo. 1. ed. Santiago de Chile: LOM Ediciones, 2012.

McDonald, P. J. Snakes on roads: An arid Australian perspective. Journal of Arid Environments, 79, 116-119, 2012. doi: 10.1016/j.jaridenv.2011.11.028

Milanez, B.; Santos, R. S. P. Neoextrativismo no Brasil? Uma análise da proposta do novo marco legal da mineração. Revista Pós Ciências Sociais, 10, 119-148, 2013.

Mill, J. S. Da liberdade. São Paulo: Instituição Brasileira de Difusão Cultural, 1963.

Ministério do Desenvolvimento Agrário - MDS. Programa Cisternas. Disponível em: <http://www.mds.gov.br/ segurancaalimentar/programa-cisternas $>$. Acesso em: jan. de 2014.

Ministério da Integração Nacional. Programa "Água para Todos" e "Operação Carro-Pipa". Disponível em: <http:// 
www.integracao.gov.br/web/guest/agua-para-todos $>$. Acesso em: jan. 2014.

Miranda, E. E. A seca e o Bolsa-Família. EcoRio, 197, 10-11, 2013.

More, T. Utopia. Cambridge: Cambridge University Press, 1989.

Muller, J. M. L'impératif de désobéissance: Fondements philosophiques et stratégiques de la désobéissance civile. Paris: Le Passager clandestin (éditions), 2011.

Oliveira, T. P. P. A longa permanência da violência como valor no sertão central pernambucano e suas relações com as territorialidades étnicas. Revista Eletrônica Tempo Presente, 7, 1-9, 2011.

Oliveira, T. P. P. Revitalização étnica e dinâmica territorial: alternativas contemporâneas à crise da economia sertaneja. 1. ed. Rio de Janeiro: Contra Capa, 2012.

Ojeda, R. A.; Tabeni, S. The mammals of the Monte Desert revisited. Journal of Arid Environments, 73, 173-181, 2009. doi: 10.1016/j.jaridenv.2007.09.008

Overbeck, G. E. Brazil's neglected biome: The South Brazilian: Campos. Perspectives in Plant Ecology, Evolution and Systematics, 9, 101-116, 2007.

Oyama, M. D.; Nobre, C. A. A new climate-vegetation equilibrium state for tropical South America. Geophysical Research Letters, 30, 23-37, 2003. doi: 10.1029/2003GL018600

Oyama, M. D.; Nobre, C. A. Climatic consequences of a large-scale desertification in northeast Brazil: a GCM simulation study. Journal of Climate, 17, 3203-3213, 2004. doi: 10.1175/1520-0442(2004)017\%3C3203:CCOALD\% 3E2.0.CO;2

Parsons, T. The social system. Glencoe: The Free Press, 1951.

Peel, M. C.; Finlayson, B. L.; McMahon, T. A. Updated world map of the Köppen-Geiger climate classification. Hydrology and Earth System Sciences, 11, 1633-1644, 2007.

Pindyck, R. S.; Rubinfeld, D. L. Microeconomia. 7. ed. São Paulo: Pearson Education do Brasil, 2012.

Rede de Manejo Florestal da Caatinga. Protocolo de medições de parcelas permanentes. Comitê Técnico-Científico. Recife: Associação Plantas do Nordeste, 2005.
Reij, C.; Tappan, G.; Belemvire, A. Changing land management practices and vegetation on the Central Plateau of Burkina Faso (1968-2002). Journal of Arid Environments, 63, 642-659, 2005. doi: 10.1016/j.jaridenv.2005.03.010

Revkin, A. The burning season: the murder of Chico Mendes and the fight for the Amazon rain forest. Washington: Island Press, 2004.

Rodal, M. J. N.; Sampaio, E. V. S. B.; Figueiredo, M. A. Manual sobre métodos de estudo florístico e fitossociológico: ecossistema caatinga. Brasília: Sociedade Botânica do Brasil, 1992.

Rodríguez, D.; Ojeda, R. A. Patterns of diversity of the Monte Desert small mammals across multiple spatial scales. Journal of Arid Environments, 75, 424-431, 2011. doi: 10.1016/j.jaridenv.2010.12.007

Saier, M. H. Desertification and Migration. Water, Air, \& Soil Pollution, 205, 31-32, 2010. doi: 10.1007/s11270-007-9429-6

Sampaio, E. V. S. B.; Araújo, M. S. B.; Sampaio, Y. S. B. Impactos ambientais da agricultura no processo de desertificação no Nordeste do Brasil. Revista de Geografia, 22(1), 90-112, 2008.

Sampaio, E. V. S. B.; Giulietti, A. M.; Virgínio, J.; Rojas, C. F. L. G. Vegetação e flora da caatinga. 1. ed. Recife: APNE-CNIP, 2002.

Sampaio, E. V. S. B.; Sampaio, Y.; Vital, T.; Araújo, M. S. B.; Sampaio, G. R. Desertificação no Brasil: conceitos, núcleos e tecnologias de recuperação e convivência. Recife: Editora Universitária UFPE, 2003.

Santos, A. S. Vulnerabilidades socioambientais diante das mudanças climáticas projetadas para o semiárido da Bahia. 153 f., il. Brasília, Dissertação (Mestrado em Desenvolvimento Sustentável) - Universidade de Brasília, 2008.

Sawyer, D. Climate change, biofuels and eco-social impacts in the Brazilian Amazon and Cerrado. Philosophical Transactions of the Royal Society B: Biological Sciences, 363, 1747-1752, 2008. doi: 10.1098/rstb.2007.0030

Scherer-Warren, I. Das mobilizações às redes de movimentos sociais. Sociedade e Estado, 21, 109-130, 2006. doi: 10.1590/S0102-69922006000100007

Scherer-Warren, I. A política dos movimentos sociais para o mundo rural. Estudos Sociedade e Agricultura, 1, 5-22, 2007. 
Scholes, R.; Kellogg, R. A natureza da narrativa. São Paulo: McGraw-Hill do Brasil, 1977.

Scott, D. M.; Waite, S.; Maddox, T. M.; Freer, R .A; Dunstone, N. The validity and precision of spotlighting for surveying desert mammal communities. Journal of Arid Environments, 61, 4, 589-601, 2005. doi: 10.1016/j. jaridenv.2004.09.008

Serviço Florestal Brasileiro. Florestas do Brasil em resumo. Brasília: Serviço Florestal Brasileiro, 2013.

Shannon, C. E.; Weaver, W. The Mathematical Theory of Communication. Urbana: University of Illinois Press, 1949.

Silva, J. A. A. Potencialidades de florestas energéticas de Eucalyptus no Polo Gesseiro do Araripe-Pernambuco. Anais da Academia Pernambucana de Ciência Agronômica, 5-6, 301-319, 2009.

Silva, J. M. C.; Tabarelli, M.; Fonseca, M. T.; Lins, L. V. Biodiversidade da caatinga: áreas e ações prioritárias para a conservação. Brasília: Ministério do Meio Ambiente e Universidade Federal de Pernambuco, 2004.

Simmel, G. Le Conflit. Lyon: Circé. 1992.

Sousa, F. P.; Ferreira, T. O.; Mendonça, E. S.; Romero, R. E.; Oliveira, J. G. B. Carbon and nitrogen in degraded Brazilian semi-arid soils undergoing desertification. Agriculture, Ecosystems \& Environment, 148, 11-21, 2012. doi: 10.1016/j.agee.2011.11.009

Sow, A. S.; Martínez-Freiría, F.; Dieng, H.; Fahd, S.; Brito, J. C. Biogeographical analysis of the Atlantic Sahara reptiles: Environmental correlates of species distribution and vulnerability to climate change. Journal of Arid Environments, 109, 65-73, 2014. doi: 10.1016/j. jaridenv.2014.05.023

Suertegaray, D. M. A. Espaço geográfico uno e múltiplo. Scripta Nova, 93, 741-98, 2001.

Tabeni, S.; Ojeda, R. A. Assessing mammal responses to perturbations in temperate aridlands of Argentina. Journal of Arid Environments, 55, 715-726, 2003. doi: 10.1016/ S0140-1963(02)00314-2

Tabeni, S.; Ojeda, R. A. Ecology of the Monte Desert small mammals in disturbed and undisturbed habitats. Journal of Arid Environments, 63, 244-255, 2005. doi: 10.1016/j. jaridenv.2005.03.009
Tacoli, C. Crisis or adaptation? Migration and climate change in a context of high mobility. Environment and Urbanization, 21, 513-525, 2009. doi: 10.1177/0956247809342182

Teyssot, G. Habits/Habitus/Habitat. Barcelona: Public Space - Centre de Cultura Contemporània de Barcelona, 1996.

Todorov, T. As estruturas narrativas. 4. ed. São Paulo: Perspectiva, 2004.

Touraine, A. La voix et le regard: Les mouvements sociaux. Paris: Les Éditions du Seuil, 1978.

Tuan, Y. Topophilia: a study of environmental perception, attitudes, and values. Englewood Cliffs: Prentice-Hall, 1974.

Vendramini, C. R. Educação e trabalho: reflexões em torno dos movimentos sociais do campo. Cadernos Cedes, 27, 121-135, 2007.

Vilela, A.; Bolkovic, M. L.; Carmanchahi, P.; Cony, M.; Lamo, D.; Wassner, D. Past, present and potential uses of native flora and wildlife of the Monte Desert. Journal of Arid Environments, 73, 238-243, 2009. doi: 10.1016/j. jaridenv.2007.10.013

Wang, G.; Zhou, Q.; Zhong, W.; Sun, C.; Chen, Z. Species richness - primary productivity relationship of plants and small mammals in the Inner Mongolian steppes, China. Journal of Arid Environments, 49, 477-484, 2001. doi: 10.1006/jare.2001.0814

Waquil, P. D.; Finco, M. V. A.; Mattos, E. J. Pobreza rural e degradação ambiental: uma refutação da hipótese do círculo vicioso. Revista de Economia e Sociologia Rural, 42, 317-340, 2004. doi: 10.1590/S0103-20032004000200007

Weber, M. Economia e sociedade: fundamentos da sociologia compreensiva. São Paulo: Imprensa Oficial do Estado de São Paulo, 2004.

Wetherell, M. Positioning and interpretative repertoires: Conversation analysis and post-structuralism in dialogue. Discourse \& Society, 9(3), 387-412, 1998.

Williams, E. Capitalismo e escravidão. 1. ed. São Paulo: Companhia das Letras, 2012.

Zullo Jr., J.; Assad, E. D.; Pinto, H. S. Dossiê Clima: alterações devem deslocar culturas agrícolas. Scientific American Brasil, 6, 72-77, 2008. 